\title{
NOTA ANATÔMICA SOBRE O CAULE DO GUAIMBÉ, PHILODENDRON BIPINNATIFIDUM SCHOTT EX ENDL. (ARACEAE) ${ }^{1}$
}

\author{
JOSÉ NEWTON CARDOSO MARCHIORI² ARACELY VIDAL GOMES ${ }^{3}$
}

\begin{abstract}
RESUMO
É descrita a estrutura anatômica do caule do guaimbé, Philodendron bipinnatifidum Schott ex Endl. (Araceae), a partir de amostra coletada no Rio Grande do Sul. Os feixes vasculares anfivasais do cilindro central, compõem-se de anel externo, com grandes traqueóides, e do floema, disposto internamente ao xilema, tendo ao centro um grupo de fibras de paredes muito espessas. Feixes menos desenvolvidos, por vezes, apresentam distribuição colateral.
\end{abstract}

Palavras-chave: Philodendron bipinnatifidum, Araceae, anatomia do caule.

\section{SUMMARY}

[Note on the stem anatomy of Philodendron bipinnatifidum Schott ex Endl. (Araceae)].

The stem anatomy of Philodendron bipinnatifidum Schott ex Endl. (Araceae) is described, based on samples from Rio Grande do Sul state, Brazil. The central cylinder of this root-climbing vine shows amphivasal vascular bundles, composed by an external ring of wide tracheids, followed by the phloem and a central zone, with thick-walled fibers. Less developed bundles, on the other way, may follow a collateral pattern.

Key words: Philodendron bipinnatifidum, Araceae, stem anatomy.

\section{INTRODUÇÃO}

Nativa da Bolívia, Paraguai, sul do Brasil e nordeste da Argentina (Jankowski et al., 2000), o guaimbé - Philodendron bipinnatifidum Schott ex Endl. - é arbusto apoiante ou epífita de ocorrência abundante e muito característica na Floresta Estacional do Alto Uruguai. Planta latescente e de grandes folhas pinatipartidas, a espécie é freqüentemente referida na literatura botânica como Philodendron selloum K. Koch, binômio atualmente reduzido à sinonímia.

$\mathrm{Na}$ estrutura florestal, o guaimbé geralmente se instala em forquilhas do tronco e ramos das árvores mais altas, emitindo longas raízes adventícias que chegam até o solo. As flores,

1 Recebido em 15-9-2008 e aceito para publicação em 20-1-2009.

2 Bolsista de Produtividade em Pesquisa do CNPq Brasil, Universidade Federal de Santa Maria. balduinia@mail.ufsm.br

3 Laboratório de Anatomia da Madeira, Universidade Federal do Paraná. reunidas em espádice axilar de $15-20 \mathrm{~cm}$ de comprimento por $4-5 \mathrm{~cm}$ de diâmetro, na parte basal (Dimitri, 1978), são protegidas por vistosa espata verde ou avermelhada por fora, branca internamente. Os frutos, crmestíveis, são bagas subcilíndricas, amarelas e de estigma persistente.

$\mathrm{O}$ presente estudo, que visa à descrição anatômica do caule do guaimbé, foi realizado a partir de amostra coletada no Rio Grande do Sul.

\section{MATERIAL E MÉTODOS}

O material em estudo, procedente do município de Derrubadas (noroeste do Rio Grande do Sul), foi coletado em área próxima ao Parque Estadual de Tenente Portela. Logo após a coleta, o segmento caulinar foi acondicionado em vidro com álcool $70 \%$, com vistas à fixação dos tecidos.

Da amostra de caule foram preparados bloquinhos, orientados para a obtenção de cortes transversais e longitudinais. Os bloquinhos 

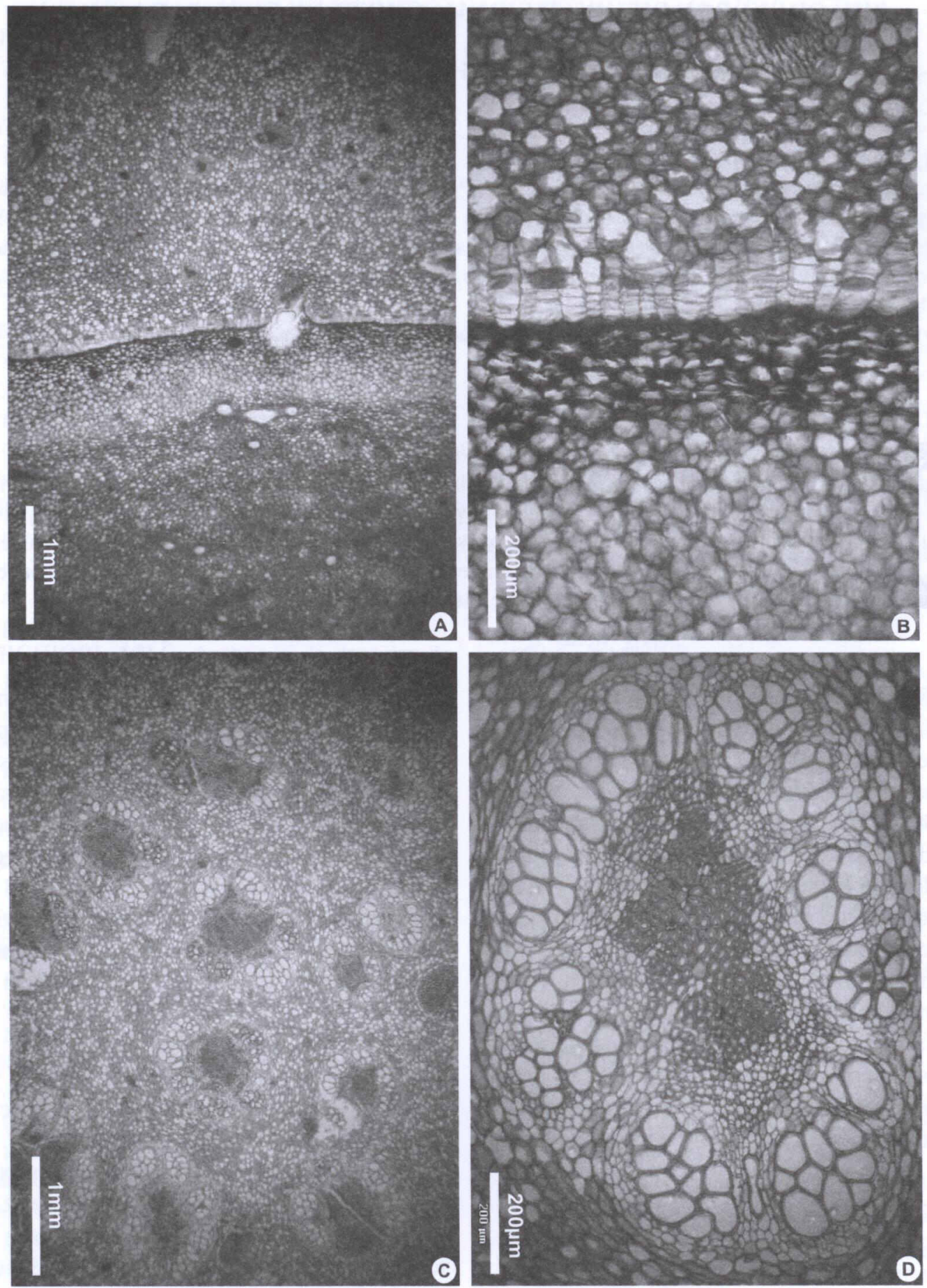

FIGURA 1 - Aspectos anatômicos do caule de Philodendron bipinnatifidum. A-Aspecto geral, com o cilindro central, na metade inferior, e o córtex, na superior. B - O meristema cicatricial, em detalhe. C-Aspecto geral do cilindro central. D - Feixe anfivasal, em detalhe. 

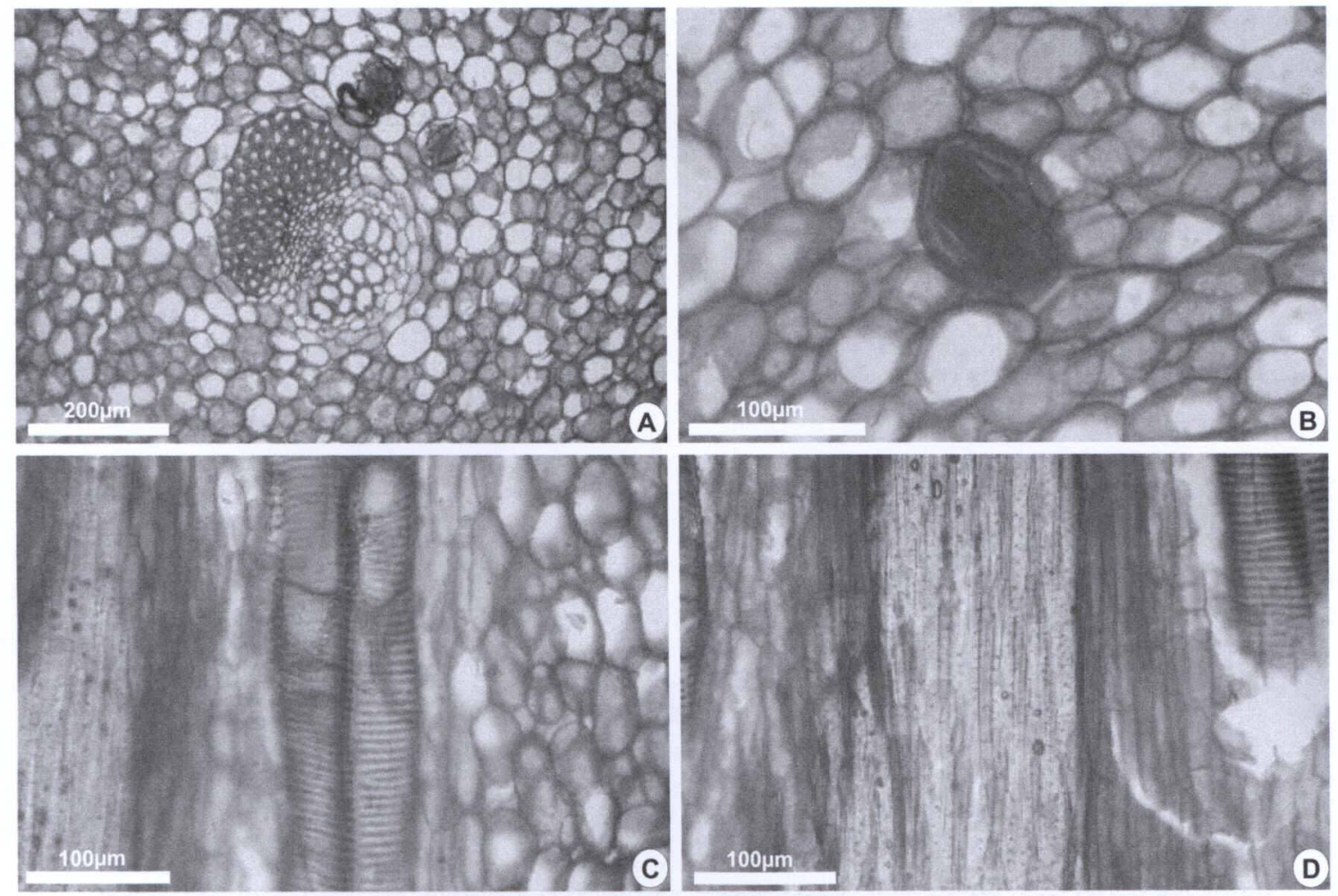

FIGURA 2 - Detalhes anatômicos do cilindro central. A - Feixe anfivasal. B - Ráfides, em idioblasto no tecido fundamental. C, D - Feixes vasculares, em cortes longitudinais.

foram fervidos em água até a expulsão completa do ar e, posteriormente, incluídos em Polietilenoglicol 1000. Os cortes anatômicos, com espessura nominal de $20 \mu \mathrm{m}$, foram obtidos em micrótomo de deslizamento, coloridos com acridina-vermelha, crisoidina e azul-de-astra (Dujardin, 1964) e montados em lâminas permanentes, com Entellan.

As fotomicrografias (Figuras 1 e 2) foram tomadas em aparelho Olympus cx 40, equipado com câmera digital Olympus Camedia c3000.

\section{DESCRIÇÃO ANATÔMICA}

Superfície caulinar com base de pecíolos ligada, na zona de abscisão, por meristema cicatricial (Figura 1B). Na região do pecíolo, observam-se traços foliares, grandes canais com mucilagem, revestidos por epitélio, e idioblastos ovais de até $150 \mu \mathrm{m}$ de diâmetro, com drusas e ráfides; estes cristais também ocorrem em células menores e arredondadas, semelhantes ao restante do tecido fundamental.

Córtex formado, basicamente, de tecido fundamental, com células parenquimáticas isodiamétricas, abundantes meatos e traços foliares (Figura 1A). Canais mucilaginosos, bem como células com drusas e ráfides, abundantes. As células cristalíferas são particularmente freqüentes na região mais externa do córtex, junto ao meristema cicatricial.

Cilindro central composto de feixes vasculares anfivasais e tecido fundamental (Figura 1C). Os feixes vasculares apresentam um anel externo de xilema, interrompido por células parenquimáticas, composto de traqueóides de grande diâmetro em agrupamentos racemiformes, que se assemelham a poros, em plano transversal (Figura 1D); em muitos 
traqueóides observam-se tilos. Em cortes longitudinais, os traqueóides apresentam pontuações transversalmente alongadas (Figura 2C, D).

O floema, disposto internamente ao xilema, forma um anel geralmente completo (Figura 1D), deixando, ao centro do feixe, um grupo de fibras de paredes muito espessas (Figura 1D). Feixes menos desenvolvidos apresentam, por vezes, distribuição colateral (Figura 2A).

No tecido fundamental, de natureza parenquimática e com células mais longas tangencialmente aos feixes vasculares (Figura 1D), distribuem-se canais mucilaginosos e idioblastos com drusas e ráfides (Figura 2B); nestes últimos, observam-se pequenas projeções mamiliformes, em ambos os polos.

\section{REFERÊNCIAS BIBLIOGRÁFICAS}

DIMITRI, M.J. Aráceas. In: DIMITRI, M.J. Enciclopedia argentina de Agricultura y Jardineria. Buenos Aires: Editorial ACME, 1978. v. 1. p. 195-207.

DUJARDIN, E.P. Eine neue Holz-Zellulosenfaerbung. Mikrokosmos, n. 53, p. 94, 1964.

JANKOWSKI, L.S.; BAZZANO, D.; SÁENZ, A.; TOURN, M.; ROITMAN, G. Plantas trepadoras. Nativas y exóticas. In: LAHITTE, H.B. \& HURRELL, J.A. (eds.). Biota Rioplatense. Buenos Aires: Editorial L.O.L.A., 2000. v. 5. 264 p.

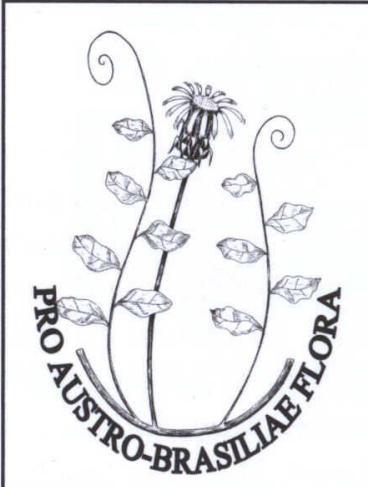

Revista científica do Herbário do Departamento de Ciências Florestais da Universidade Federal de Santa Maria, Balduinia visa a contribuir para a Botânica sul-brasileira com publicações originais nas áreas de Taxonomia Vegetal, Fitogeografia e Anatomia da Madeira. O nome do periódico presta merecida homenagem a Balduíno Rambo, um dos mais importantes botânicos brasileiros do século vinte.

Solicita-se permuta / Exchange desired 